JORGE LUIZ CECCON

\title{
ANÁLISE DOS EFEITOS DE SEGUNDA ORDEM EM PILARES SOLICITADOS A FLEXÃO OBLÍQUA COMPOSTA
}

\author{
Tese apresentada à \\ Escola Politécnica da \\ Universidade de São Paulo \\ para obtenção do título de \\ Doutor em Engenharia.
}

Orientador: Prof. Ricardo Leopoldo e Silva França

Departamento de Engenharia de Estruturas e Fundações, EPUSP

São Paulo

2008 